\title{
Demiclosedness principle and approximation theorems for certain classes of multivalued mappings in Hilbert spaces
}

\section{Felicia O Isiogugu ${ }^{*}$}

\section{"Correspondence:}

obifeli2001@yahoo.com

Department of Mathematics,

University of Nigeria, Nsukka,

Nigeria

\begin{abstract}
We prove weak and strong convergence theorems and the demiclosedness property for classes of multivalued mappings $T$ such that $P_{T}$ is not nonexpansive, where $P_{T X}=\{u \in T x:\|x-u\|=d(x, T x)\}$. Thus our results extend and improve the results on multivalued and single-valued mappings in the contemporary literature.

MSC: $47 \mathrm{H} 10 ; 54 \mathrm{H} 25$

Keywords: proximinal sets; Hilbert spaces; nonexpansive-type mappings; $k$-strictly pseudocontractive-type mappings; pseudocontractive-type mappings
\end{abstract}

\section{Introduction}

Let $E$ be a normed space. A subset $K$ of $E$ is called proximinal if for each $x \in E$ there exists $k \in K$ such that

$$
\|x-k\|=\inf \{\|x-y\|: y \in K\}=d(x, K) .
$$

It is known that every closed convex subset of a uniformly convex Banach space is proximinal. In fact, if $K$ is a closed and convex subset of a uniformly convex Banach space $X$, then for any $x \in X$ there exists a unique point $u_{x} \in K$ such that (see, e.g., $[1,2]$ )

$$
\left\|x-u_{x}\right\|=\inf \{\|x-y\|: y \in K\}=d(x, K) .
$$

We will denote the family of all nonempty proximinal subsets of $X$ by $P(X)$, the family of all nonempty closed, convex and bounded subsets of $X$ by $\operatorname{CVB}(X)$, the family of all nonempty closed and bounded subsets of $X$ by $\mathrm{CB}(X)$ and the family of all nonempty subsets of $X$ by $2^{X}$ for a nonempty set $X$. Let $\mathrm{CB}(E)$ be the family of all nonempty closed and bounded subsets of a normed space $E$. Let $H$ be the Hausdorff metric induced by the metric $d$ on $E$, that is, for every $A, B \in 2^{E}$,

$$
H(A, B)=\max \left\{\sup _{a \in A} d(a, B), \sup _{b \in B} d(b, A)\right\}
$$

If $A, B \in \mathrm{CB}(E)$, then

$$
H(A, B)=\inf \{\epsilon>0: A \subseteq N(\epsilon, B) \text { and } B \subseteq N(\epsilon, A)\}
$$

( 2013 Isiogugu; licensee Springer. This is an Open Access article distributed under the terms of the Creative Commons Attribution License (http://creativecommons.org/licenses/by/2.0), which permits unrestricted use, distribution, and reproduction in any medium, provided the original work is properly cited. 
where $N(\epsilon, C)=\bigcup_{c \in C}\{x \in E: d(x, c) \leq \epsilon\}$. Let $E$ be a normed space. Let $T: D(T) \subseteq E \rightarrow 2^{E}$ be a multivalued mapping on $E$. A point $x \in D(T)$ is called a fixed point of $T$ if $x \in T x$. The set $F(T)=\{x \in D(T): x \in T x\}$ is called a fixed point set of $T$. A point $x \in D(T)$ is called a strict fixed point of $T$ if $T x=\{x\}$. The set $F_{s}(T)=\{x \in D(T): T x=\{x\}\}$ is called a strict fixed point set of $T$. A multivalued mapping $T: D(T) \subseteq E \rightarrow 2^{E}$ is called L-Lipschitzian if there exists $L>0$ such that, for any pair $x, y \in D(T)$,

$$
H(T x, T y) \leq L\|x-y\|
$$

In (1) if $L \in[0,1), T$ is said to be a contraction, while $T$ is nonexpansive if $L=1 . T$ is called quasi-nonexpansive if $F(T)=\{x \in D(T): x \in T x\} \neq \emptyset$ and, for all $p \in F(T)$,

$$
H(T x, T p) \leq\|x-p\|
$$

Clearly, every nonexpansive mapping with nonempty fixed point set is quasi-nonexpansive.

In recent years, several works have been done on the approximation of fixed points of multivalued nonexpansive mappings by many authors (see, for example, [3-5] and references therein). Different iterative schemes have been introduced by several authors to approximate the fixed points of nonexpansive mappings (see, for example, [3-5]). Among the iterative schemes, Sastry and Babu [3] introduced Mann and Ishikawa iteration as follows.

Let $T: X \rightarrow P(X)$ and $p$ be a fixed point of $T$. The sequence of Mann iterates is given for $x_{0} \in X$ by

$$
x_{n+1}=\left(1-\alpha_{n}\right) x_{n}+\alpha_{n} y_{n} \quad \forall n \geq 0,
$$

where $y_{n} \in T x_{n}$ is such that $\left\|y_{n}-p\right\|=d\left(T x_{n}, p\right)$ and $\alpha_{n}$ is a real sequence in $(0,1) \sum_{n=1}^{\infty} \alpha_{n}=$ $\infty$.

The sequence of Ishikawa iterates is given by

$$
\left\{\begin{array}{l}
y_{n}=\left(1-\beta_{n}\right) x_{n}+\beta_{n} z_{n}, \\
x_{n+1}=\left(1-\alpha_{n}\right) x_{n}+\alpha_{n} u_{n},
\end{array}\right.
$$

where $z_{n} \in T x_{n}, u_{n} \in T y_{n}$ are such $\left\|z_{n}-p\right\|=d\left(p, T x_{n}\right),\left\|u_{n}-p\right\|=d\left(T y_{n}, p\right)$ and $\left\{\alpha_{n}\right\},\left\{\beta_{n}\right\}$ are real sequences satisfying: (i) $0 \leq \alpha_{n}, \beta_{n}<1$; (ii) $\lim _{n \rightarrow \infty} \beta_{n}=0$; (iii) $\sum_{n=1}^{\infty} \alpha_{n} \beta=\infty$.

Using the above iterative schemes, Panyanak [4] generalized the result proved by [3].

Nadler [6] made the following useful remark.

Lemma 1 Let $A, B \in \mathrm{CB}(X)$ and $a \in A$. If $\gamma>0$, then there exists $b \in B$ such that

$$
d(a, b) \leq H(A, B)+\gamma .
$$

Using Lemma 1, Song and Wang [5] modified the iteration process due to Panyanak [4] and improved the results therein. They made the important observation that generating the Mann and Ishikawa sequences in [3] is in some sense dependent on the knowledge of the fixed point. They gave their iteration scheme as follows. 
Let $K$ be a nonempty convex subset of $X$, let $\alpha_{n}, \beta_{n} \in[0,1]$ and $\gamma_{n} \in(0, \infty)$ such that $\lim _{n \rightarrow \infty} \gamma_{n}=0$. Choose $x_{1} \in K, z_{1} \in T x_{1}$. Let

$$
y_{1}=\left(1-\beta_{1}\right) x_{1}+\beta_{1} z_{1}
$$

Choose $u_{1} \in T y_{1}$ such that $\left\|z_{1}-u_{1}\right\| \leq H\left(T x_{1}, T y_{1}\right)+\gamma_{1}$ and

$$
x_{2}=\left(1-\alpha_{1}\right) x_{1}+\alpha_{1} u_{1} .
$$

Choose $z_{2} \in T x_{2}$ such that $\left\|z_{2}-u_{1}\right\| \leq H\left(T x_{2}, T y_{1}\right)+\gamma_{2}$ and

$$
y_{2}=\left(1-\beta_{2}\right) x_{2}+\beta_{2} z_{2}
$$

Choose $u_{2} \in T y_{2}$ such that $\left\|z_{2}-u_{2}\right\| \leq H\left(T x_{2}, T y_{2}\right)+\gamma_{2}$ and

$$
x_{3}=\left(1-\alpha_{2}\right) x_{2}+\alpha_{1} u_{2} .
$$

Inductively, we have

$$
\left\{\begin{array}{l}
y_{n}=\left(1-\beta_{n}\right) x_{n}+\beta_{n} z_{n} \\
x_{n+1}=\left(1-\alpha_{n}\right) x_{n}+\alpha_{n} u_{n}
\end{array}\right.
$$

where $z_{n} \in T x_{n}, u_{n} \in T y_{n}$ satisfy $\left\|z_{n}-u_{n}\right\| \leq H\left(T x_{n}, T y_{n}\right)+\gamma_{n},\left\|z_{n+1}-u_{n}\right\| \leq H\left(T x_{n+1}, T y_{n}\right)+$ $\gamma_{n}$ and $\left\{\alpha_{n}\right\},\left\{\beta_{n}\right\}$ are real sequences in $[0,1)$ satisfying $\lim _{n \rightarrow \infty} \beta_{n}=0, \sum_{n=1}^{\infty} \alpha_{n} \beta_{n}=\infty$.

Using the above iteration, they then proved the following theorem.

Theorem 1 (Theorem 1, [5]) Let $K$ be a nonempty compact convex subset of a uniformly convex Banach space $X$. Suppose that $T: K \rightarrow \mathrm{CB}(K)$ is a multivalued nonexpansive mapping such that $F(T) \neq \emptyset$ and $T(p)=\{p\}$ for all $p \in F(T)$. Then the Ishikawa sequence defined as above converges strongly to a fixed point of $T$.

Shahzad and Zegeye [7] observed that if $X$ is a normed space and $T: D(T) \subseteq E \rightarrow P(X)$ is any multivalued mapping, then the mapping $P_{T}: D(T) \rightarrow P(X)$ defined for each $x$ by

$$
P_{T}(x)=\{y \in T x: d(x, T x)=\|x-y\|\}
$$

has the property that $P_{T}(q)=\{q\}$ for all $q \in F(T)$. Using this idea, they removed the strong condition ' $T(p)=\{p\}$ for all $p \in F(T)$ ' introduced by Song and Wang [5].

Recently, Khan and Yildirim [8] introduced a new iteration scheme for multivalued nonexpansive mappings using the idea of the iteration scheme for a single-valued nearly asymptotically nonexpansive mapping introduced by Agarwal et al. [9] as follows:

$$
\left\{\begin{array}{l}
x_{1} \in K, \\
x_{n+1}=(1-\lambda) v_{n}+\lambda u_{n}, \\
y_{n}=(1-\eta) x_{n}+\eta v_{n} \quad \forall n \in \mathbb{N},
\end{array}\right.
$$

where $v_{n} \in P_{T}\left(x_{n}\right), u_{n} \in P_{T}\left(y_{n}\right)$ and $\lambda \in[0,1)$. Also, using a lemma in Schu [10], the idea of removal of the condition ' $T(p)=\{p\}$ for all $p \in F(T)$ ' introduced by Shahzad and Zegeye 
[7] and the method of direct construction of a Cauchy sequence as indicated by Song and Cho [11], they stated the following theorems.

Theorem 2 (Theorem 1, [8]) Let X be a uniformly convex Banach space satisfying Opial's condition and $K$ be a nonempty closed convex subset of $X$. Let $T: K \rightarrow P(K)$ be a multivalued mapping such that $F(T) \neq \emptyset$ and $P_{T}$ is a nonexpansive mapping. Let $\left\{x_{n}\right\}$ be the sequence as defined in (7). Let $\left(I-P_{T}\right)$ be demiclosed with respect to zero. Then $\left\{x_{n}\right\}$ converges weakly to a point of $F(T)$.

However, we observe that there are many multivalued mappings $T$ for which neither $T$ nor $P_{T}$ is nonexpansive. Based on the above observation, it is our purpose in this paper to firstly introduce the new classes of multivalued nonexpansive-type, $k$-strictly pseudocontractive-type and pseudocontractive-type mappings which are more general than the class of multivalued nonexpansive mappings. Secondly, we prove that if $H$ is a real Hilbert space and $K$ is a nonempty weakly closed subset of $H, T: K \subseteq H \rightarrow P(H)$ is a multivalued mapping from $K$ into the family of all nonempty proximinal subsets of $H$. Suppose that $P_{T}$ is a $k$-strictly pseudocontractive-type mapping. Then $\left(I-P_{T}\right)$ is demiclosed at zero (i.e., the graph of $I-P_{T}$ is closed at zero in $\sigma\left(E, E^{*}\right) \times(E,\|\cdot\|)$ or weakly demiclosed at zero), where $I$ denotes the identity on $E, \sigma\left(E, E^{*}\right)$ the weak topology, $(E,\|\cdot\|)$ the norm (or strong) topology and $P_{T} x=\{u \in T x:\|x-u\|=d(x, T x)\}$. Lastly, we prove weak and strong convergence theorems for these classes of multivalued mappings without the compactness condition on the domain of the mappings using Mann and Ishikawa iteration schemes. Thus our results extend and improve the results on single-valued and multivalued mappings in the contemporary literature.

In the sequel, we will need the following definitions and lemmas.

Definition 1 (See, e.g., [12]) Let $E$ be a Banach space. Let $T: D(T) \subseteq E \rightarrow 2^{E}$ be a multivalued mapping. $I-T$ is said to be strongly demiclosed at zero if for any sequence $\left\{x_{n}\right\}_{n=1}^{\infty} \subseteq D(T)$ such that $x_{n}$ converges strongly to $p$ and a sequence $\left\{y_{n}\right\}$ with $y_{n} \in T x_{n}$ for all $n \in \mathbb{N}$ such that $\left\{x_{n}-y_{n}\right\}$ converges strongly to zero, then $p \in T p$ (i.e., $\left.F(T) \neq \emptyset\right)$.

Observe that if $T$ is a multivalued Lipschitzian mapping, then $I-T$ is strongly demiclosed.

Definition 2 (See, e.g., $[12,13]$ ) Let $E$ be a Banach space. Let $T: D(T) \subseteq E \rightarrow 2^{E}$ be a multivalued mapping. $I-T$ is said to be weakly demiclosed at zero if for any sequence $\left\{x_{n}\right\}_{n=1}^{\infty} \subseteq D(T)$ such that $\left\{x_{n}\right\}$ converges weakly to $p$ and a sequence $\left\{y_{n}\right\}$ with $y_{n} \in T x_{n}$ for all $n \in \mathbb{N}$ such that $\left\{x_{n}-y_{n}\right\}$ converges strongly to zero, then $p \in T p(i . e ., 0 \in(I-T) p)$.

Definition 3 Let $E$ be a Banach space. Let $T: D(T) \subseteq E \rightarrow 2^{E}$ be a multivalued mapping. A point $p \in E$ is called an asymptotic fixed point of $T$ if there exists a sequence $\left\{x_{n}\right\}_{n=1}^{\infty} \subseteq$ $D(T)$ such that $\left\{x_{n}\right\}$ converges weakly to $p$ and a sequence $\left\{y_{n}\right\}$ with $y_{n} \in T x_{n}$ for all $n \in \mathbb{N}$ such that $\left\{x_{n}-y_{n}\right\}$ converges strongly to zero. We denote the set of asymptotic fixed points of $T$ by $\widehat{F}(T)$.

Definition 4 (See, e.g., $[12,13]$ ) Let $E$ be a Banach space. Let $T: D(T) \subseteq E \rightarrow 2^{E}$ be a multivalued mapping. The graph of $I-T$ is said to be closed in $\sigma\left(E, E^{*}\right) \times(E,\|\cdot\|)$ (i.e., $I-T$ is weakly demiclosed or demiclosed) if for any sequence $\left\{x_{n}\right\}_{n=1}^{\infty} \subseteq D(T)$ such that $\left\{x_{n}\right\}$ 
converges weakly to $p$ and a sequence $\left\{y_{n}\right\}$ with $y_{n} \in T x_{n}$ for all $n \in \mathbb{N}$ such that $\left\{x_{n}-y_{n}\right\}$ converges strongly to $y$, then $y \in(I-T) p$ (i.e., $y=p-v$ for some $v \in T p$ ).

Definition 5 ([14]) Let $H$ be a real Hilbert space. Let $T: H \rightarrow \mathrm{CB}(H)$ be a multivalued mapping. $T$ is said to be monotone if given $x, y \in H$ and $u \in T x$, there exists $v \in T y$ such that

$$
\begin{aligned}
& \langle u-v, x-y\rangle \geq 0, \\
& d(x, T x) \geq f(d(x, F(T)) \quad \forall x \in K .
\end{aligned}
$$

Definition 6 ([5]) A multivalued mapping $T: K \rightarrow P(K)$ is said to satisfy condition (1) (see, for example, [5]) if there exists a nondecreasing function $f:[0, \infty) \rightarrow[0, \infty)$ with $f(0)=0$ and $f(r)>0$ for all $r \in(0, \infty)$ such that

$$
d(x, T x) \geq f(d(x, F(T)) \quad \forall x \in K .
$$

Definition 7 Let $E$ be a real Banach space. Let $T: E \rightarrow 2^{E}$ be a multivalued mapping. $I-T$ is said to be monotone in the sense of [14] if given any pair $x, y \in E$ and $u \in T x$, there exists $v \in T y$ such that

$$
\langle x-u-(y-v), x-y\rangle \geq 0
$$

Lemma 2 ([15]) Let $\left\{a_{n}\right\},\left\{\beta_{n}\right\}$ and $\left\{\gamma_{n}\right\}$ be sequences of nonnegative real numbers satisfying the following relation:

$$
a_{n+1} \leq\left(1+\beta_{n}\right) a_{n}+\gamma_{n}, \quad n \geq n_{0},
$$

where $n_{0}$ is a nonnegative integer. If $\sum \beta_{n}<\infty, \sum \gamma_{n}<\infty$, then $\lim _{n \rightarrow \infty} a_{n}$ exists.

Lemma 3 ([11]) Let $K$ be a normed space. Let $T: K \rightarrow P(K)$ be a multivalued mapping and $P_{T}(x)=\{y \in T x:\|x-y\|=d(x, T x)\}$. Then the following are equivalent:

(1) $x \in T x$;

(2) $P_{T} x=\{x\}$

(3) $x \in F\left(P_{T}\right)$.

Moreover, $F(T)=F\left(P_{T}\right)$.

Lemma 4 Let $H$ be a real Hilbert space. Then the following well-known result holds: if $\left\{x_{n}\right\}_{n=1}^{\infty}$ is a sequence in $H$ which converges weakly to $z \in H$, then

$$
\lim \sup _{n \rightarrow \infty}\left\|x_{n}-y\right\|^{2}=\lim \sup _{n \rightarrow \infty}\left\|x_{n}-z\right\|^{2}+\|z-y\|^{2} \quad \forall y \in H .
$$

\section{Main results}

Definition 8 Let $X$ be a normed space. A multivalued mapping $T: D(T) \subseteq X \rightarrow 2^{X}$ is said to be $k$-strictly pseudocontractive-type in the sense of Browder and Petryshyn [16] if there 
exists $k \in[0,1)$ such that given any $x, y \in D(T)$ and $u \in T x$, there exists $v \in T y$ satisfying $\|u-v\| \leq H(T x, T y)$ and

$$
H^{2}(T x, T y) \leq\|x-y\|^{2}+k\|x-u-(y-v)\|^{2} .
$$

If $k=1$ in (9), $T$ is said to be a pseudocontractive-type mapping. $T$ is called nonexpansivetype if $k=0$. Clearly, every multivalued nonexpansive mapping is a nonexpansive-type mapping.

From the definitions, it is clear that every multivalued nonexpansive-type mapping is $k$-strictly pseudocontractive-type and every $k$-strictly pseudocontractive-type mapping is pseudocontractive-type. The following examples show that the class of nonexpansive-type mappings is properly contained in the class of $k$-strictly pseudocontractive-type mappings and the class of $k$-strictly pseudocontractive-type mappings is properly contained in the class of pseudocontractive-type mappings.

Example 1 Let $X=\mathbb{R}$ (the reals with usual metric). Define $T:[0, \infty) \rightarrow 2^{\mathbb{R}}$ by

$$
T x=\left[-\frac{5 x}{2},-2 x\right]
$$

Then $P_{T} x=\{-2 x\}$ for all $x \in[0, \infty)$, hence it is not nonexpansive.

$$
\begin{aligned}
H^{2}(T x, T y) & =\max \left\{|2(x-y)|^{2},\left|\frac{5}{2}(x-y)\right|^{2}\right\} \\
& =\frac{25}{4}|x-y|^{2}=|x-y|^{2}+\frac{21}{4}|x-y|^{2} .
\end{aligned}
$$

Also, for each $u \in T x, u=-\alpha x, 2 \leq \alpha \leq \frac{5}{2}$, choose $v=-\alpha y$. Then

$$
|u-v|=|-\alpha x-(-\alpha y)|=\alpha|x-y| \leq \frac{5}{2}|x-y|=H(T x, T y)
$$

and

$$
\begin{aligned}
|x-u-(y-v)|^{2} & =|x-(-\alpha x)-(y-(-\alpha y))|^{2} \\
& =|(1+\alpha) x-(1+\alpha) y|^{2}=(1+\alpha)^{2}|x-y|^{2} .
\end{aligned}
$$

Hence

$$
\begin{aligned}
H^{2}(T x, T y) & =|x-y|^{2}+\frac{21}{4}|x-y|^{2} \\
& =|x-y|^{2}+\frac{21}{4(1+\alpha)^{2}}(1+\alpha)^{2}|x-y| \\
& =|x-y|^{2}+\frac{21}{4(1+\alpha)^{2}}|x-u-(y-v)|^{2} \\
& \leq|x-y|^{2}+\frac{21}{4(1+2)^{2}}|x-u-(y-v)|^{2} \\
& =|x-y|^{2}+\frac{7}{12}|x-u-(y-v)|^{2} .
\end{aligned}
$$


Consequently, $T$ is $k$-strictly pseudocontractive-type with $k=\frac{7}{12}$. It then follows that $T$ is pseudocontractive-type. Observe that $T$ is not nonexpansive-type so that the class of multivalued nonexpansive-type mappings is properly contained in the class of multivalued $k$-strictly pseudocontractive-type mappings. Next, we show that the class of multivalued pseudocontractive-type mappings properly contains the class of multivalued $k$ strictly pseudocontractive-type mappings.

Example 2 Let $X=\mathbb{R}$ (the reals with usual metric). Define $T:[0, \infty) \rightarrow 2^{\mathbb{R}}$ by

$$
T x=[-\sqrt{10} x,-2 x]
$$

Then $P_{T} x=\{-2 x\}$ which is not nonexpansive. Also,

$$
H^{2}(T x, T y)=\max \left\{|\sqrt{10}(x-y)|^{2},|2(x-y)|^{2}\right\}=10|x-y|^{2}=|x-y|^{2}+9|x-y|^{2} .
$$

Furthermore, for each $u \in T x, u=-\alpha x, 2 \leq \alpha \leq \sqrt{10}$, choose $v=-\alpha y$. Then

$$
|u-v|=|-\alpha x-(-\alpha y)|=\alpha|x-y| \leq \sqrt{10}|x-y|=H(T x, T y)
$$

and

$$
|x-u-(y-v)|^{2}=|x-(-\alpha x)-(y-(-\alpha y))|^{2}=|(1+\alpha) x-(1+\alpha) y|^{2}=(1+\alpha)^{2}|x-y|^{2} .
$$

It then follows that

$$
\begin{aligned}
H^{2}(T x, T y) & =|x-y|^{2}+9|x-y|^{2} \\
& =|x-y|^{2}+(1+2)^{2}|x-y|^{2} \\
& \leq|x-y|^{2}+(1+\alpha)^{2}|x-y|^{2} \\
& =|x-y|^{2}+|x-u-(y-v)|^{2} .
\end{aligned}
$$

Now, for any pair $x, 0 \in[0, \infty), T 0=\{0\}$. It then follows that for any $u \in T x$ the corresponding $v=0$. In particular, for $u=-2 x$,

$$
\begin{aligned}
H^{2}(T x, T 0) & =10|x-0|^{2} \\
& =|x-0|^{2}+9|x-0|^{2} \\
& =|x-0|^{2}+|x-(-2 x)|^{2} \\
& =|x-0|^{2}+|x-u-(y-v)|^{2} \\
& >|x-y|^{2}+k|x-u-(y-v)|^{2} \quad \forall k \in(0,1) .
\end{aligned}
$$

It then follows that $T$ is a pseudocontractive-type mapping but not a $k$-strictly pseudocontractive-type mapping.

Using the multivalued version of the method of the proof used in [17], we then prove the following. 
Proposition 1 Let E be a real Banach space. Suppose $T: D(T) \subset E \rightarrow 2^{E}$ is a pseudocontractive-type mapping. Then $I-T$ is monotone.

Proof Since $T$ is pseudocontractive-type, for any pair $x, y \in D(T)$ and $u \in T x$, there exists $v \in T y$ such that

$$
\|u-v\|^{2} \leq H^{2}(T x, T y) \leq\|x-y\|^{2}+\|x-u-(y-v)\|^{2} .
$$

Now,

$$
\begin{aligned}
\|u-v\|^{2} & =\|x-y\|^{2}+\|x-u-(y-v)\|^{2}-2\langle x-u-(y-v), x-y\rangle \\
& \leq\|x-y\|^{2}+\|x-u-(y-v)\|^{2} .
\end{aligned}
$$

Hence, $\langle x-u-(y-v), x-y\rangle \geq 0$. Hence, $I-T$ is monotone.

Proposition 2 Let $E$ be a normed space. And let $T: D(T) \subseteq E \rightarrow 2^{E}$ be a k-strictly pseudocontractive-type mapping. Then $T$ is a L-Lipschitzian mapping.

Proof Let $T$ be a $k$-strictly pseudocontractive-type mapping. Then there exists $k \in[0,1)$ such that, for all $x, y \in D(T)$ and $u \in T x$, there exists $v \in T y$ satisfying $\|u-v\| \leq H(T x, T y)$ and

$$
H^{2}(T x, T y) \leq\|x-y\|^{2}+k\|x-u-(y-v)\|^{2} .
$$

We then have that

$$
\begin{aligned}
H^{2}(T x, T y) & \leq\|x-y\|^{2}+k\|x-u-(y-v)\|^{2} \\
& \leq[\|x-y\|+\sqrt{k}\|x-u-(y-v)\|]^{2} .
\end{aligned}
$$

It then follows that

$$
\begin{aligned}
H(T x, T y) & \leq\|x-y\|+\sqrt{k}[\|x-y\|+\|u-v\|] \\
& \leq\|x-y\|+\sqrt{k}[\|x-y\|+H(T x, T y)] .
\end{aligned}
$$

Hence

$$
H(T x, T y) \leq \frac{(1+\sqrt{k})}{(1-\sqrt{k})}\|x-y\|
$$

Proposition 3 Let $H$ be a real Hilbert space. Let $K$ be a nonempty weakly closed subset of $H$. Let $T: K \subseteq H \rightarrow P(H)$ be a multivalued mapping from $K$ into the family of all nonempty proximinal subsets of $H$. Suppose that $P_{T}$ is a $k$-strictly pseudocontractive-type mapping. Then $\left(I-P_{T}\right)$ is demiclosed at zero (i.e., the graph of $I-P_{T}$ is closed at zero in $\sigma\left(E, E^{*}\right) \times(E,\|\cdot\|)$ or weakly demiclosed at zero $)$. 
Proof Let $\left\{x_{n}\right\}_{n=1}^{\infty} \subseteq K$ be such that $\left\{x_{n}\right\}$ converges weakly to $p$ and a sequence $\left\{y_{n}\right\}$ with $y_{n} \in P_{T} x_{n}$ for all $n \in \mathbb{N}$ such that $\left\{x_{n}-y_{n}\right\}$ converges strongly to 0 . We prove that $0 \in$ $\left(I-P_{T}\right) p$ (i.e., $p=v$ for some $\left.v \in P_{T} p\right)$. Since $\left\{x_{n}\right\}_{n=1}^{\infty}$ converges weakly, it is bounded. Let $q \in P_{T} p$ be arbitrary. From the definition of $k$-strictly pseudocontractive-type, for each $n \in \mathbb{N}$, there exists $v_{n} \in P_{T} x_{n}$ such that

$$
\left\|v_{n}-q\right\| \leq H\left(P_{T} x_{n}, P_{T} p\right)
$$

and

$$
H^{2}\left(P_{T} x_{n}, P_{T} p\right) \leq\left\|x_{n}-p\right\|^{2}+k\left\|x_{n}-v_{n}-(p-q)\right\|^{2}
$$

for all $n \in \mathbb{N}$. Also, since $v_{n}, y_{n} \in P_{T} x_{n},\left\|x_{n}-v_{n}\right\|=\left\|x_{n}-y_{n}\right\|$. Thus we have

$$
\lim _{n \rightarrow \infty}\left\|x_{n}-v_{n}\right\|=\lim _{n \rightarrow \infty}\left\|x_{n}-y_{n}\right\|=0 .
$$

For each $x \in X$, define $f: E \rightarrow[0, \infty)$ by

$$
f(x):=\limsup _{n \rightarrow \infty}\left\|x_{n}-x\right\|^{2} .
$$

Then, from Lemma 4, we obtain

$$
f(x)=\limsup _{n \rightarrow \infty}\left\|x_{n}-p\right\|^{2}+\|p-x\|^{2} \quad \forall x \in E .
$$

Thus

$$
f(x)=f(p)+\|p-x\|^{2} \quad \forall x \in E .
$$

Therefore,

$$
f(q)=f(p)+\|p-q\|^{2} .
$$

Observe also that

$$
\begin{aligned}
f(q) & =\limsup _{n \rightarrow \infty}\left\|x_{n}-q\right\|^{2} \\
& =\limsup _{n \rightarrow \infty}\left\|x_{n}-v_{n}+\left(v_{n}-q\right)\right\|^{2} \\
& =\limsup _{n \rightarrow \infty}\left\|v_{n}-q\right\|^{2} \\
& \leq \limsup _{n \rightarrow \infty} H^{2}\left(P_{T} x_{n}, P_{T} p\right) \\
& \leq \limsup _{n \rightarrow \infty}\left[\left\|x_{n}-p\right\|^{2}+k\left\|x_{n}-v_{n}-(p-q)\right\|^{2}\right] \\
& =\limsup _{n \rightarrow \infty}\left\|x_{n}-p\right\|^{2}+k\|(p-q)\|^{2} \\
& =f(p)+k\|p-q\|^{2} .
\end{aligned}
$$

Hence it follows from (14) and (15) that $(1-k)\|p-q\|^{2}=0$. Therefore $p=q \in T p$. 
Theorem 3 Let $K$ be a nonempty closed and convex subset of a real Hilbert space H. Suppose that $T: K \rightarrow P(K)$ is a $k$-strictly pseudocontractive-type mapping from $K$ into the family of all proximinal subsets of $K$ with $k \in(0,1)$ such that $F(T) \neq \emptyset$ and $T(p)=\{p\}$ for all $p \in F(T)$. Suppose (I-T) is weakly demiclosed at zero. Then the Mann type sequence defined by

$$
x_{n+1}=\left(1-\alpha_{n}\right) x_{n}+\alpha_{n} y_{n}
$$

converges weakly to $q \in F(T)$, where $y_{n} \in T x_{n}$ with $\left\|x_{n}-y_{n}\right\|=d\left(x_{n}, T x_{n}\right)$ and $\alpha_{n}$ is a real sequence in $(0,1)$ satisfying: (i) $\alpha_{n} \rightarrow \alpha<1-k$; (ii) $\alpha>0$; (iii) $\sum_{n=1}^{\infty} \alpha_{n}\left(1-\alpha_{n}\right)=\infty$.

Proof Using the well-known identity

$$
\|t x+(1-t) y\|^{2}=t\|x\|^{2}+(1-t)\|y\|^{2}-t(1-t)\|x-y\|^{2},
$$

which holds for all $x, y \in H$ and for all $t \in[0,1]$, we obtain

$$
\begin{aligned}
\left\|x_{n+1}-p\right\|^{2}= & \left\|\left(1-\alpha_{n}\right) x_{n}+\alpha_{n} y_{n}-p\right\|^{2} \\
= & \left\|\left(1-\alpha_{n}\right)\left(x_{n}-p\right)+\alpha_{n}\left(y_{n}-p\right)\right\|^{2} \\
= & \left(1-\alpha_{n}\right)\left\|x_{n}-p\right\|^{2}+\alpha_{n}\left\|y_{n}-p\right\|^{2}-\alpha_{n}\left(1-\alpha_{n}\right)\left\|x_{n}-y_{n}\right\|^{2} \\
\leq & \left(1-\alpha_{n}\right)\left\|x_{n}-p\right\|^{2}+\alpha_{n} H^{2}\left(T x_{n}, T p\right)-\alpha_{n}\left(1-\alpha_{n}\right)\left\|x_{n}-y_{n}\right\|^{2} \\
\leq & \left(1-\alpha_{n}\right)\left\|x_{n}-p\right\|^{2}+\alpha_{n}\left[\left\|x_{n}-p\right\|^{2}+k d^{2}\left(x_{n}, T x_{n}\right)\right] \\
& -\alpha_{n}\left(1-\alpha_{n}\right)\left\|x_{n}-y_{n}\right\|^{2} \\
\leq & \left\|x_{n}-p\right\|^{2}+\alpha_{n} k\left\|x_{n}-y_{n}\right\|^{2} \\
& -\alpha_{n}\left(1-\alpha_{n}\right)\left\|x_{n}-y_{n}\right\|^{2} \\
= & \left\|x_{n}-p\right\|^{2}-\alpha_{n}\left(1-\left(\alpha_{n}+k\right)\right)\left\|x_{n}-y_{n}\right\|^{2} .
\end{aligned}
$$

It then follows that $\lim _{n \rightarrow \infty}\left\|x_{n}-p\right\|$ exists, hence $\left\{x_{n}\right\}$ is bounded. Also,

$$
\sum_{n=1}^{\infty} \alpha_{n}\left(1-\left(\alpha_{n}+k\right)\right)\left\|x_{n}-y_{n}\right\|^{2} \leq\left\|x_{0}-p\right\|^{2} \leq \infty .
$$

Since $\alpha>0$, from (ii), we have that $\lim _{n \rightarrow \infty}\left\|x_{n}-y_{n}\right\|=0$. Also, since $K$ is closed and $\left\{x_{n}\right\} \subseteq$ $K$ with $\left\{x_{n}\right\}$ bounded, there exists a subsequence $\left\{x_{n_{t}}\right\} \subseteq\left\{x_{n}\right\}$ such that $\left\{x_{n_{t}}\right\}$ converges weakly to some $q \in K$. Also, $\lim _{n \rightarrow \infty}\left\|x_{n}-y_{n}\right\|=0$ implies that $\lim _{n \rightarrow \infty}\left\|x_{n_{t}}-y_{n_{t}}\right\|=0$. Since $(I-T)$ is weakly demiclosed at zero, we have that $q \in T q$. Since $H$ satisfies Opial's condition [18], we have that $\left\{x_{n}\right\}$ converges weakly to $q \in F(T)$.

Corollary 1 Let $H$ be a real Hilbert space and $K$ be a nonempty closed and convex subset of $H$. Let $T: K \rightarrow P(K)$ be a multivalued mapping from $K$ into the family of all proximinal subsets of $K$ with $F(T) \neq \emptyset$. Suppose $P_{T}$ is a $k$-strictly pseudocontractive-type mapping with $k \in(0,1)$. Then the Mann sequence $\left\{x_{n}\right\}$ defined in Theorem 3 converges weakly to a point of $F(T)$. 
Proof The proof follows easily from Lemma 3, Proposition 3 and Theorem 3.

Remark 1 It is easy to see that Examples 1 and 2 satisfy the condition 'given any pair $x, y \in D(T)$ and $u \in T x$ with $\|x-u\|=d(x, T x)$, there exists $v \in T y$ with $\|y-v\|=d(y, T y)$ satisfying the conditions of Definition 8. Also, if $T$ is a multivalued mapping such that $P_{T}$ is a pseudocontractive-type mapping, then given any pair $x, y \in D(T)$ and $u \in P_{T} x$ with the corresponding $v \in P_{T} y$ satisfying the conditions of Definition 8 , it is the case that $\|x-u\|=$ $d\left(x, P_{T} x\right)$ and $\|y-v\|=d\left(y, P_{T} y\right)$.

Based on Lemma 3 and Remark 1 above, we will first prove weak and strong convergence for the new class of pseudocontractive-type mappings with the following two conditions: (i) given any pair $x, y \in D(T)$ and $u \in T x$ with $\|x-u\|=d(x, T x)$, there exists $v \in T y$ with $\|y-v\|=d(y, T y)$ satisfying the conditions of Definition 8; (ii) $T(p)=\{p\}$ for all $p \in F(T)$, then obtain the case for an arbitrary multivalued mapping $T$ such that $P_{T}$ is a pseudocontractive-type mapping without the two conditions on $P_{T}$ as corollary.

Theorem 4 Let $K$ be a nonempty closed and convex subset of a real Hilbert space X. Suppose that $T: K \rightarrow P(K)$ is an L-Lipschitzian pseudocontractive-type mapping from $K$ into the family of all proximinal subsets of $K$ such that $F(T) \neq \emptyset$ and $T(p)=\{p\}$ for all $p \in F(T)$. Suppose, for any pair $x, y \in K$ and $u \in T x$ with $\|x-u\|=d(x, T x)$, there exists $v \in T y$ with $\|y-v\|=d(y, T y)$ satisfying the conditions of Definition 8 . Suppose T satisfies condition (1). Then the Ishikawa sequence defined by

$$
\left\{\begin{array}{l}
y_{n}=\left(1-\beta_{n}\right) x_{n}+\beta_{n} u_{n} \\
x_{n+1}=\left(1-\alpha_{n}\right) x_{n}+\alpha_{n} w_{n}
\end{array}\right.
$$

converges strongly to $p \in F(T)$, where $u_{n} \in T x_{n}$ with $\left\|x_{n}-u_{n}\right\|=d\left(x_{n}, T x_{n}\right), w_{n} \in T y_{n}$ with $\left\|y_{n}-w_{n}\right\|=d\left(y_{n}, T y_{n}\right)$ satisfying the conditions in Definition 8 and $\left\{\alpha_{n}\right\}$ and $\left\{\beta_{n}\right\}$ are real sequences satisfying: (i) $0 \leq \alpha_{n} \leq \beta_{n}<1$; (ii) $\liminf _{n \rightarrow \infty} \alpha_{n}=\alpha>0$; (iii) $\sup _{n \geq 1} \beta_{n} \leq \beta \leq$ $\frac{1}{\sqrt{1+L^{2}}+1}$.

Proof

$$
\begin{aligned}
\left\|x_{n+1}-p\right\|^{2}= & \left\|\left(1-\alpha_{n}\right) x_{n}+\alpha_{n} w_{n}-p\right\|^{2} \\
= & \left\|\left(1-\alpha_{n}\right)\left(x_{n}-p\right)+\alpha_{n}\left(w_{n}-p\right)\right\|^{2} \\
= & \left(1-\alpha_{n}\right)\left\|x_{n}-p\right\|^{2}+\alpha_{n}\left\|w_{n}-p\right\|^{2} \\
& -\alpha_{n}\left(1-\alpha_{n}\right)\left\|x_{n}-w_{n}\right\|^{2} \\
\leq & \left(1-\alpha_{n}\right)\left\|x_{n}-p\right\|^{2}+\alpha_{n} H^{2}\left(T y_{n}, T p\right) \\
& -\alpha_{n}\left(1-\alpha_{n}\right)\left\|x_{n}-w_{n}\right\|^{2} \\
\leq & \left(1-\alpha_{n}\right)\left\|x_{n}-p\right\|^{2}+\alpha_{n}\left[\left\|y_{n}-p\right\|^{2}\right. \\
& \left.+d^{2}\left(y_{n}, T y_{n}\right)\right]-\alpha_{n}\left(1-\alpha_{n}\right)\left\|x_{n}-w_{n}\right\|^{2} \\
= & \left(1-\alpha_{n}\right)\left\|x_{n}-p\right\|^{2}+\alpha_{n}\left\|y_{n}-p\right\|^{2}+\alpha_{n} d^{2}\left(y_{n}, T y_{n}\right) \\
& -\alpha_{n}\left(1-\alpha_{n}\right)\left\|x_{n}-w_{n}\right\|^{2} .
\end{aligned}
$$


Also,

$$
\begin{aligned}
d^{2}\left(y_{n}, T y_{n}\right) \leq & \left\|y_{n}-w_{n}\right\|^{2} \\
= & \left\|\left(1-\beta_{n}\right) x_{n}+\beta_{n} u_{n}-w_{n}\right\|^{2} \\
= & \left\|\left(1-\beta_{n}\right)\left(x_{n}-w_{n}\right)+\beta_{n}\left(u_{n}-w_{n}\right)\right\|^{2} \\
= & \left(1-\beta_{n}\right)\left\|x_{n}-w_{n}\right\|^{2}+\beta_{n}\left\|u_{n}-w_{n}\right\|^{2} \\
& -\beta_{n}\left(1-\beta_{n}\right)\left\|x_{n}-u_{n}\right\|^{2} .
\end{aligned}
$$

(17) and (18) imply that

$$
\begin{aligned}
\left\|x_{n+1}-p\right\|^{2} \leq & \left(1-\alpha_{n}\right)\left\|x_{n}-p\right\|^{2}+\alpha_{n}\left\|y_{n}-p\right\|^{2} \\
& +\alpha_{n}\left[\left(1-\beta_{n}\right)\left\|x_{n}-w_{n}\right\|^{2}+\beta_{n}\left\|u_{n}-w_{n}\right\|^{2}\right. \\
& \left.-\beta_{n}\left(1-\beta_{n}\right)\left\|x_{n}-u_{n}\right\|^{2}\right] \\
& -\alpha_{n}\left(1-\alpha_{n}\right)\left\|x_{n}-w_{n}\right\|^{2}, \\
\left\|y_{n}-p\right\|^{2}= & \left\|\left(1-\beta_{n}\right) x_{n}+\beta_{n} u_{n}-p\right\|^{2} \\
= & \left\|\left(1-\beta_{n}\right)\left(x_{n}-p\right)+\beta_{n}\left(u_{n}-p\right)\right\|^{2} \\
= & \left(1-\beta_{n}\right)\left\|x_{n}-p\right\|^{2}+\beta_{n}\left\|u_{n}-p\right\|^{2} \\
& -\beta_{n}\left(1-\beta_{n}\right)\left\|x_{n}-u_{n}\right\|^{2} \\
\leq & \left(1-\beta_{n}\right)\left\|x_{n}-p\right\|^{2}+\beta_{n} H^{2}\left(T x_{n}, T p\right) \\
& -\beta_{n}\left(1-\beta_{n}\right)\left\|x_{n}-u_{n}\right\|^{2}, \\
\leq & \left(1-\beta_{n}\right)\left\|x_{n}-p\right\|^{2}+\beta_{n}\left[\left\|x_{n}-p\right\|^{2}+d^{2}\left(x_{n}, T x_{n}\right)\right] \\
& -\beta_{n}\left(1-\beta_{n}\right)\left\|x_{n}-u_{n}\right\|^{2} \\
\leq & \left(1-\beta_{n}\right)\left\|x_{n}-p\right\|^{2}+\beta_{n}\left\|x_{n}-p\right\|^{2}+\beta_{n}\left\|x_{n}-u_{n}\right\|^{2} \\
& -\beta_{n}\left(1-\beta_{n}\right)\left\|x_{n}-u_{n}\right\|^{2} \\
= & \left\|x_{n}-p\right\|^{2}+\beta_{n}^{2}\left\|x_{n}-u_{n}\right\|^{2} .
\end{aligned}
$$

(19) and (20) imply that

$$
\begin{aligned}
\left\|x_{n+1}-p\right\|^{2} \leq & \left(1-\alpha_{n}\right)\left\|x_{n}-p\right\|^{2} \\
& +\alpha_{n}\left[\left\|x_{n}-p\right\|^{2}+\beta_{n}^{2}\left\|x_{n}-u_{n}\right\|^{2}\right] \\
& +\alpha_{n}\left[\left(1-\beta_{n}\right)\left\|x_{n}-w_{n}\right\|^{2}+\beta_{n}\left\|u_{n}-w_{n}\right\|^{2}\right. \\
& \left.-\beta_{n}\left(1-\beta_{n}\right)\left\|x_{n}-u_{n}\right\|^{2}\right] \\
& -\alpha_{n}\left(1-\alpha_{n}\right)\left\|x_{n}-w_{n}\right\|^{2} \\
= & \left(1-\alpha_{n}\right)\left\|x_{n}-p\right\|^{2}+\alpha_{n}\left\|x_{n}-p\right\|^{2}+\alpha_{n} \beta_{n}^{2}\left\|x_{n}-u_{n}\right\|^{2} \\
& +\alpha_{n}\left(1-\beta_{n}\right)\left\|x_{n}-w_{n}\right\|^{2}+\alpha_{n} \beta_{n}\left\|u_{n}-w_{n}\right\|^{2}
\end{aligned}
$$




$$
\begin{aligned}
& -\alpha_{n} \beta_{n}\left(1-\beta_{n}\right)\left\|x_{n}-u_{n}\right\|^{2}-\alpha_{n}\left(1-\alpha_{n}\right)\left\|x_{n}-w_{n}\right\|^{2} \\
\leq & \left\|x_{n}-p\right\|^{2}+\alpha_{n} \beta_{n}^{2}\left\|x_{n}-u_{n}\right\|^{2}+\alpha_{n} \beta_{n} H^{2}\left(T x_{n}, T y_{n}\right) \\
& -\alpha_{n}\left(\beta_{n}-\alpha_{n}\right)\left\|x_{n}-w_{n}\right\|^{2} \\
& -\alpha_{n} \beta_{n}\left(1-\beta_{n}\right)\left\|x_{n}-u_{n}\right\|^{2} \\
\leq & \left\|x_{n}-p\right\|^{2}+\alpha_{n} \beta_{n}^{2}\left\|x_{n}-u_{n}\right\|^{2}+\alpha_{n} \beta_{n}^{3} L^{2}\left\|x_{n}-u_{n}\right\|^{2} \\
& -\alpha_{n} \beta_{n}\left(1-\beta_{n}\right)\left\|x_{n}-u_{n}\right\|^{2} \\
& -\alpha_{n}\left(\beta_{n}-\alpha_{n}\right)\left\|x_{n}-w_{n}\right\|^{2} \\
= & \left\|x_{n}-p\right\|^{2}-\alpha_{n} \beta_{n}\left[1-2 \beta_{n}-L^{2} \beta_{n}^{2}\right]\left\|x_{n}-u_{n}\right\|^{2} \\
& -\alpha_{n}\left(\beta_{n}-\alpha_{n}\right)\left\|x_{n}-w_{n}\right\|^{2} \\
= & \left\|x_{n}-p\right\|^{2}-\alpha_{n} \beta_{n}\left[1-2 \beta_{n}-L^{2} \beta_{n}^{2}\right]\left\|x_{n}-u_{n}\right\|^{2} .
\end{aligned}
$$

It then follows from Lemma 2 that $\lim _{n \rightarrow \infty}\left\|x_{n}-p\right\|$ exists. Hence $\left\{x_{n}\right\}$ is bounded, so are $\left\{u_{n}\right\}$ and $\left\{w_{n}\right\}$. We then have from (21), (ii) and (iii) that

$$
\begin{aligned}
\sum_{n=0}^{\infty} \alpha^{2}\left[1-2 \beta-L^{2} \beta^{2}\right]\left\|x_{n}-u_{n}\right\|^{2} & \leq \sum_{n=0}^{\infty} \alpha_{n} \beta_{n}\left[1-2 \beta_{n}-L^{2} \beta_{n}^{2}\right]\left\|x_{n}-u_{n}\right\|^{2} \\
& \leq \sum_{n=0}^{\infty}\left[\left\|x_{n}-p\right\|^{2}-\left\|x_{n+1}-p\right\|^{2}\right] \\
& \leq\left\|x_{0}-p\right\|^{2}+D<\infty .
\end{aligned}
$$

It then follows that $\lim _{n \rightarrow \infty}\left\|x_{n}-u_{n}\right\|=0$. Since $u_{n} \in T x_{n}$, we have that $d\left(x_{n}, T x_{n}\right) \leq \| x_{n}-$ $u_{n} \| \rightarrow 0$ as $n \rightarrow \infty$. Since $T$ satisfies condition (1), $\lim _{n \rightarrow \infty} d\left(x_{n}, F(T)\right)=0$. Thus there exists a subsequence $\left\{x_{n_{k}}\right\}$ of $\left\{x_{n}\right\}$ such that $\left\|x_{n_{k}}-p_{k}\right\| \leq \frac{1}{2^{k}}$ for some $\left\{p_{k}\right\} \subseteq F(T)$. From $(21)$

$$
\left\|x_{n_{k+1}}-p_{k}\right\| \leq\left\|x_{n_{k}}-p_{k}\right\|
$$

We now show that $\left\{p_{k}\right\}$ is a Cauchy sequence in $F(T)$.

$$
\begin{aligned}
\left\|p_{k+1}-p_{k}\right\| & \leq\left\|p_{k+1}-x_{n_{k+1}}\right\|+\left\|x_{n_{k+1}}-p_{k}\right\| \\
& \leq \frac{1}{2^{k+1}}+\frac{1}{2^{k}}=\frac{1}{2^{k-1}} .
\end{aligned}
$$

Therefore $\left\{p_{k}\right\}$ is a Cauchy sequence and converges to some $q \in K$ because $K$ is closed. Now,

$$
\left\|x_{n_{k}}-q\right\| \leq\left\|x_{n}-p_{k}\right\|+\left\|p_{k}-q\right\| .
$$

Hence $x_{n_{k}} \rightarrow q$ as $k \rightarrow \infty$,

$$
\begin{aligned}
d(q, T q) & \leq\left\|q-p_{k}\right\|+\left\|p_{k}-x_{n_{k}}\right\|+d\left(x_{n_{k}}, T x_{n_{k}}\right)+H\left(T x_{n_{k}}, T q\right) \\
& \leq\left\|q-p_{k}\right\|+\left\|p_{k}-x_{n_{k}}\right\|+d\left(x_{n_{k}}, T x_{n_{k}}\right)+L\left\|x_{n_{k}}-q\right\| .
\end{aligned}
$$


Hence, $q \in T q$ and $\left\{x_{n_{k}}\right\}$ converges strongly to $q$. Since $\lim \left\|x_{n}-q\right\|$ exists, we have that $x_{n}$ converges strongly to $q \in F(T)$.

Corollary 2 Let $H$ be a real Hilbert space and $K$ be a nonempty closed and convex subset of $H$. Let $T: K \rightarrow P(K)$ be a multivalued mapping from $K$ into the family of all proximinal subsets of $K$ such that $F(T) \neq \emptyset$. Suppose $P_{T}$ is an L-Lipschitzian pseudocontractive-type mapping. If $T$ satisfies condition (1), then the Ishikawa sequence $\left\{x_{n}\right\}$ defined in (16) converges strongly to $p \in F(T)$.

Proof The proof follows easily from Lemma 3, Remark 1 and Theorem 4.

\section{Competing interests}

The author declares that they have no competing interests.

\section{Acknowledgements}

This work was carried out at the University of Kwazulu Natal, South Africa when the author visited under the OWSDW [formally TWOWS], Abdus Salam International Centre for Theoretical Physics (ICTP) Trieste, Italy, Postgraduate Training Fellowship. She is grateful to OWSDW for the Fellowship and to University of Kwazulu Natal for making their facilities available and for hospitality.

Received: 19 July 2012 Accepted: 24 February 2013 Published: 18 March 2013

\section{References}

1. Landers, D, Rogge, L: Martingale representation in uniformly convex Banach spaces. Proc. Am. Math. Soc. 75(1), 108-110 (1979)

2. Fitzpatrick, S: Metric projections and the differentiability of distance functions. Bull. Aust. Math. Soc. 22, 291-312 (1980)

3. Sastry, KPR, Babu, GVR: Convergence of Ishikawa iterates for a multivalued mapping with a fixed point. Czechoslov, Math. J. 55, 817-826 (2005)

4. Panyanak, B: Mann and Ishikawa iteration processes for multivalued mappings in Banach spaces. Comput. Math. Appl. 54, 872-877 (2007)

5. Song, Y, Wang, H: Erratum to "Mann and Ishikawa iterative processes for multivalued mappings in Banach spaces" [Comput. Math. Appl. 54, 872-877 (2007)]. Comput. Math. Appl. 55, 2999-3002 (2008)

6. Nadler, SB Jr.: Multivalued contraction mappings. Pac. J. Math. 30, 475-488 (1969)

7. Shahzad, N, Zegeye, $\mathrm{H}$ : On Mann and Ishikawa iteration schemes for multi-valued mappings in Banach spaces. Nonlinear Anal. 71(3-4), 838-844 (2009)

8. Khan, SH, Yildirim, I: Fixed points of multivalued nonexpansive mappings in a Banach spaces. Fixed Point Theory Appl. 2012, 73 (2012). doi:10.1186/1687-1812-2012-73

9. Agarwal, RP, O'Regan, D, Sabu, DR: Iterative construction of fixed points of nearly asymptotically nonexpansive mappings. J. Nonlinear Convex Anal. 8(1), 61-79 (2007)

10. Schu, J: Weak and strong convergence to fixed points of asymptotically nonexpansive mappings. Bull. Aust. Math. Soc 43, 153-159 (1991)

11. Song, Y, Cho, YJ: Some notes on Ishikawa iteration for multivalued mappings. Bull. Korean Math. Soc. 48(3), 575-584 (2011). doi:10.4134/BKMS.2011.48.3.575

12. Garcia-Falset, J, Lorens-Fuster, E, Suzuki, T: Fixed point theory for a class of generalized nonexpansive mappings. J. Math. Anal. Appl. 375, 185-195 (2011)

13. Dozo, EL: Multivalued nonexpansive mappings and Opial's condition. Proc. Am. Math. Soc. 38(2), 286-292 (1973)

14. Markin, JT: A fixed point theorem for set valued mappings. Bull. Am. Math. Soc. 74, 639-640 (1968)

15. Tan, KK, Xu, HK: Approximating fixed points of nonexpansive mappings by the Ishikawa iteration process. J. Math. Anal. Appl. 178, 301-308 (1993)

16. Browder, FE, Petryshyn, WV: Construction of fixed points of nonlinear mappings in Hilbert spaces. J. Math. Anal. Appl. 20, 197-228 (1967)

17. Osilike, MO, Isiogugu, FO: Weak and strong convergence theorems for nonspreading-type mappings in Hilbert spaces. Nonlinear Anal. 74, 1814-1822 (2011)

18. Opial, Z: Weak convergence of the sequence of successive approximations for nonexpansive mappings. Bull. Am. Math. Soc. 73, 591-597 (1967)

doi:10.1186/1687-1812-2013-61

Cite this article as: Isiogugu: Demiclosedness principle and approximation theorems for certain classes of

multivalued mappings in Hilbert spaces. Fixed Point Theory and Applications 2013 2013:61. 